\title{
Is Thrombolytic Therapy appropriate at the Late Phase of Cardiopulmonary Resuscitation for Massive Pulmonary Thromboembolism?
}

\author{
Abuzer Coskun ${ }^{*}$, Sevki Hakan Eren ${ }^{2}$ \\ 'Department of Emergency, Sivas Numune Hospital, Sivas, Turkey \\ ${ }^{2}$ Department of Emergency Medicine, Gaziantep University, Gaziantep, Turkey
}

\section{Article Info}

\section{Article Notes}

Received: January 11, 2020

Accepted: February 06, 2020

\section{*Correspondence:}

Dr. Abuzer Coskun, Department of Emergency, Sivas Numune Hospital, Sivas, Turkey;

Email: dr.acoskun44@hotmail.com.

${ }^{\circ} 2020$ Coskun A. This article is distributed under the terms of the Creative Commons Attribution 4.0 International License.

\section{Keywords:}

Emergency department

Pulmonary thromboembolism

Cardiopulmonary resuscitation

Late thrombolytic therapy
Abstract

Pulmonary thromboembolism in which hemostatic balance is disrupted is a disease with high morbidity and mortality rates with challenging diagnosis. A 73-year-old female patient presented to the emergency department with respiratory distress. She had undergone surgery for femoral neck fracture three months ago. She had gradually aggravating respiratory distress for the last 3-4 days. The patient was admitted to the hospital with the diagnosis of massive pulmonary embolism. She had a cardiac arrest after completion of thoracic computed tomography (thoracic CT). Cardiopulmonary resuscitation (CPR) was initiated. Alteplase (rt-PA) was infused at $100 \mathrm{mg} / 2$ hours starting at the 37th minute of CPR in the late phase. As there was no room on the wards, she was admitted to the emergency room observation unit and extubated on the 9th day. Coumadin (warfarin) dose was adjusted and the patient was discharged on day 17 with an INR (International Normalized Ratio) of 2.3.

\section{Introduction}

Pulmonary embolism (PE) is a condition where the pulmonary artery and/or its branches are obstructed usually by a thrombus and sometimes a non-thrombotic material such as air, fat, tumor cell, amniotic fluid and septic materials transported by the systemic veins $^{1,2}$. The origin of the thrombus is usually the deep venous system in the lower extremity and pelvis. If the thrombus affects a large area, it can lead to massive PE resulting in a mortality of up to $15 \%$. Obstructive shock and severe right ventricular failure are the most important mechanisms in cardiac arrest due to massive $\mathrm{PE}^{3}$.

Thrombolytics are used in the treatment in cases of shock and hypotension in $\mathrm{PE}^{4}$. Thrombolytics which were previously considered contraindicated in cardiac arrest due to $\mathrm{PE}$, have been proposed as a treatment option in recent studies ${ }^{5,6}$.

In this case report, we aimed to present in the light of the literature a case with cardiac arrest due to PE and who received CPR and was administered thrombolytic therapy without any late complication.

\section{Case Report}

A 73-year-old female patient presented to the emergency department with respiratory distress. She had undergone surgery for femoral neck fracture three months ago. She had gradually aggravating respiratory distress for the last 3-4 days. The patient's blood pressure was $70 / 40 \mathrm{mmHg}$ with a heart rate of $117 /$ minute and a respiration rate of $32 /$ minute. Fine rales were heard at the 
lower lungs and the heart was tachyarrhythmic. The skin was cold, pale and sweaty. Oxygen saturation was $67 \%$. Massive PE was considered as the preliminary diagnosis. The patient was quickly stabilized and a thoracic computed tomographic angiography was obtained. However, the patient had a cardiac arrest immediately after the procedure. Cardiopulmonary resuscitation was initiated and a response was obtained at the 37 th minute of the CPR. Consultation was requested from the Cardiology, Pulmonary Diseases and Intensive Care Unit but the patient could be admitted to neither of those clinics since no hospital beds were available.

Arterial blood gas revealed respiratory alkalosis, hypoxia and hypocapnia.

Electrocardiography demonstrated a tachycardia, right bundle branch block and right loading.

Laboratory findings were as follows: D-dimer: $10457 \mathrm{ng} / \mathrm{ml}$, troponin I: $0.93 \mathrm{ng} / \mathrm{ml}$. Blood glucose: $178 \mathrm{mg} /$ $\mathrm{dl}$, Blood Urea Nitrogen (BUN): $42 \mathrm{mg} / \mathrm{dl}$, Creatinine: $1.57 \mathrm{mg} / \mathrm{dl}$, Alanine Aminotransferase: $168 \mathrm{U} / \mathrm{L}$, Aspartate Aminotransferase: $1530 \mathrm{U} / \mathrm{L}$, Alkaline Phosphatase: 341U/L. White Blood Cells: $19200\left(\times 10^{3} \mu \mathrm{L}\right)$, Platelets: $204000(\mathrm{x} 10)^{3}$ Neutrophils: 13.4 (\%) and Lymphocytes: $4.9(\%)$.

Information was given to the relatives of the patient and it was decided to start thrombolytic therapy after obtaining the required informed consent. Alteplase (rtPA; recombinant tissue type plasminogen activator) infusion of which we haven't encountered any use at the emergency service in the literature was started in a dose of $100 \mathrm{mg} / 2$ hours. She was admitted to the emergency room observation unit and mechanical ventilator settings were made. She was extubated on the 9th day after followup. Her Coumadin (Warfarin) dose was adjusted for 8 days and she was discharged on the 17 th day with an INR (International Normalized Ratio) of 2.3.

Computed tomography of the patient revealed an appearance consistent with massive embolism in the left main pulmonary artery (Figure 1).

\section{Discussion}

Cardiac arrest due to pulmonary embolism carries a very high rate of mortality. $50-70 \%$ of cases of cardiac arrest are due to acute myocardial infarction and $\mathrm{PE}^{7,8}$. Thrombolytics have been used successfully in the treatment of PE and myocardial infarction. Although the use of thrombolytics has been reported in the literature to be relatively contraindicated in prolonged CPR, recent studies have shown beneficial effects also in cases that underwent CPR. If PE is considered, thrombolytic therapy should also be considered ${ }^{5}$. Thrombolytic therapy was explained to our patient in the diagnosis of possible PE.
Figure 1: Pulmonary embolism in the left main pulmonary artery

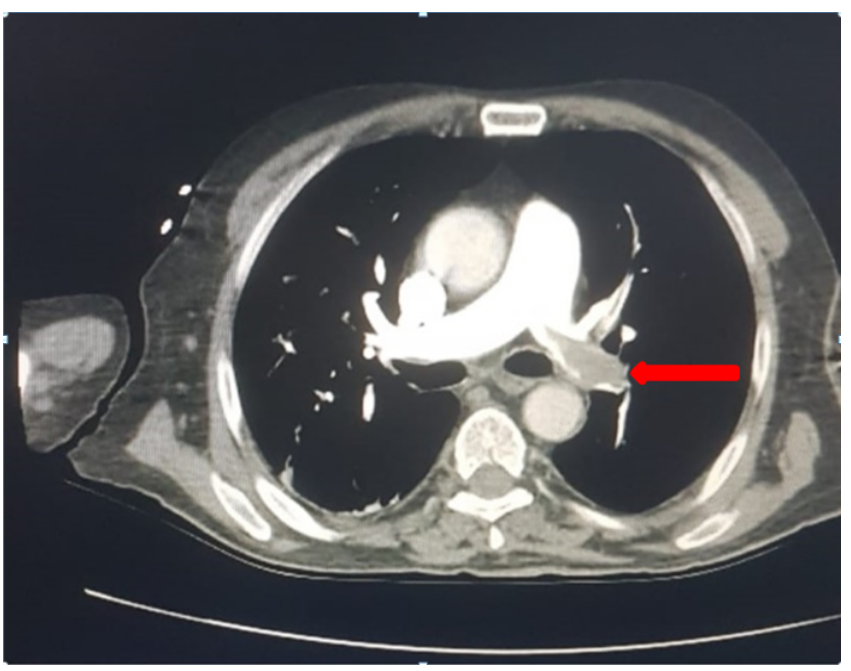

Contrast-enhanced thoracic computed tomography, thrombus material in the area indicated by the arrow in the left main pulmonary artery in axial section.

Arrest developed immediately after thoracic CT. Massive $\mathrm{PE}$ was seen in CT. Informing consent was obtained from the family. After prolonged CPR, thrombolytic was applied, no complications developed and successful presentation was received.

Many studies have been conducted on thrombolytic therapy and contradictory results have been obtained. In a similar study, 21 patients with cardiac arrest due to massive PE underwent thrombolytic therapy during CPR and showed a significant difference in the return of spontaneous circulation compared to a control group ${ }^{9}$. There was no significant difference between groups that were administered placebo and thrombolytics in TROICA's study in 1050 patients. Bleeding was significantly higher in the thrombolytic group. Accordingly, no routine use of thrombolytic therapy in cardiac arrest cases has been recommended ${ }^{10}$. Thrombolytics were reported to be possibly useful when the cardiac arrest was due to pulmonary embolism in a meta-analysis of cases with CPR and treated with thrombolytics and heparin ${ }^{11}$.

There is still no consensus in the use of thrombolytic drugs. Turkish Thoracic Society recommends infusion of the drug at a rate of $50 \mathrm{mg} / 2$ hours ${ }^{2}$, while American Heart Association and European Society of Cardiology recommend $100 \mathrm{mg} / 2$ hours, and $100 \mathrm{mg} / 2$ hours or $0.6 \mathrm{mg} / \mathrm{kg}$ in 15 minutes, respectively ${ }^{12}$. In our case, alteplase (rt-PA) was infused at a rate of $100 \mathrm{mg} / 2$ hours in accordance with the literature and no complications were observed.

\section{Conclusion}

We have seen that thrombolytic therapy can be used in both PE and acute coronary syndromes in the prolonged late periods of CPR. We suggest in light of the literature 
findings that although thrombolytic therapy during CPR is a subject that still needs to be evaluated, it should be considered in cases of cardiac arrest due to PE.

\section{References}

1. Karen KK Sheares. How do I manage a patient with suspected acute pulmonary embolism? Clinical Medicine. 2011; 11(2): 156-9.

2. Jorens PG, Van Mark E, Snoecks A, et al. Nonthrombotic pulmonary embolism ERJ. 2009; 34(2): 452-474.

3. Turkish Thoracic Society Pulmonary Thromboembolism Diagnosis and Reconciliation Report. 2015; 5(22,11): 49-50.

4. Lualdi JC, Goldhaber SZ. Right ventricular dysfunction after acute pulmonary embolism: pathophysiologic factors, detection, and therapeutic implications. Am Heart J. 1995; 130: 1276-1282.

5. Er F, Nia AM, Gassanov N, et al. Impact of Rescue-Thrombolysis during Cardiopulmonary Resuscitation in Patients with Pulmonary Embolism. PLoS ONE. 2009; 4(12): 8323.

6. Torbicki A, Perrier A, Konstantinides S, et al. Guidelines on the diagnosis and management of acute pulmonary embolism: the Task Force for the Diagnosis and Management of Acute Pulmonary Embolism of the European Society of Cardiology ESC. Eur Heart J. 2008; 29: 2276-2315.
7. Kasper W, Konstantinides S, Geibel A, et al. Management strategies and determinants of outcome in acute major pulmonary embolism: results of a multicenter registry. J Am Coll Cardiol. 1997; 30: 11651171.

8. Spöhr F, Böttifer BW. Emergency Medicine and myocardial ischemiathrombolysis during cardiopulmonary resuscitation-available data and recommendations. Anasthesiol Intensivmed Notfallmed Schmertzher. 2008; 43(3): 226-30.

9. Kürkciyan I, Mercan G, Sterz F, et al. Pulmonary embolism asa a cause of cardiac arrest: presentation and outcome. Arch Intern Med. 2000; 22; 160(10): 1529-35.

10. Bottiger BW, Arntz HR, Chamberlain DA, et al. Thrombolysis during resuscitation for out-of-hospital cardiac arrest. The New England J of Med. 2008; 359 (25): 2651-62.

11. Weidmann JL, Shook DC, Hiberath JN. Cardiac resuscitation and coagulation. Anesthesiology. 2014; $120: 4$.

12. Konstantinides SV, Torbicki A, Agnelli G, et al. Task Force for the Diagnosis and Management of Acute Pulmonary Embolism of the European Society of Cardiology ESC ESC guidelines on the diagnosis and management of acute pulmonary embolism. Eur Heart J. 2014; 35(43): 3033-69. 